\section{Ensino remoto emergencial e formação de professores de línguas adicionais}

Emergency distance learning and additional language teacher training

\section{Marina Lopes Ribeiro (D) 9}

maribeiro@id.uff.br

Universidade Federal Fluminense - UFF

\section{Stephanie Godiva (D) 9}

stephaniegodiva@id.uff.br

Universidade Federal Fluminense - UFF

\section{Ebal Sant'Anna Bolacio Filho (D) 9 \\ ebolacio@gmail.com}

Universidade Federal Fluminense - UFF

\section{Resumo}

A suspensão abrupta do ensino presencial nas universidades a fim de conter a rápida propagação da COVID-19 trouxe inúmeros desafios, dentre eles, a reestruturação dos cursos de idiomas oferecidos ao público externo à universidade para seu oferecimento na modalidade online em caráter emergencial. O presente trabalho apresenta um relato de experiência acerca do ensino de alemão num dos cursos de extensão de uma universidade federal e analisa as percepções de alunos e professores em formação vinculados a esse projeto durante o ensino remoto. Para tal, foi aplicado um questionário online semiaberto aos professores-tutores e alunos. As análises indicam que a despeito das dificuldades encontradas, há entre os sujeitos de pesquisa uma percepção positiva da experiência online.

\section{Palavras-chave}

Ensino de língua adicional. Formação docente. Ensino remoto emergencial.

\section{Abstract}

The abrupt suspension of in-person teaching at universities in order to contain the sudden spread of COVID-19 brought many challenges, among them, the remodeling of language courses offered to the outside community to the university to be offered in the online format in an emergency context. This paper proposes to present an experience report on the teaching of German in one of the extension courses at a federal university and to analyze the perceptions of students and teachers in training linked to this project during remote teaching. To achieve this, an online semi-open questionnaire was applied to the teacher-tutors and students.The analyses indicate that despite the difficulties encountered, there is a positive perception of the online experience within the research participants.

\section{Keywords}

Additional language teaching. Teacher training. Emergency distance learning.

\section{Linguagęm Foco}

Revista do Programa de Pós-Graduação em Linguística Aplicada da UECE

FLUXO DA SUBMISSÃO

Submissão do trabalho: $28 / 02 / 2021$ Aprovação do trabalho: 17/05/2021 Publicação do trabalho: 04/06/2021

\section{COMO CITAR}

RIBEIRO, Marina Lopes; GODIVA, Stephanie; BOLACIO FILHO, Ebal Sant'Anna. Ensino remoto emergencial e formação de professores de línguas adicionais. Revista Linguagem em Foco, v.13, n.1, 2021. p. 237-256. Disponívelem:https://revistas. uece.br/index.php/linguagememfoco/article/view/5010. 


\section{Introdução}

A rápida propagação do coronavírus (COVID-19) pelo mundo no início de 2020 promoveu uma das maiores crises de saúde pública dos últimos anos. A fim de conter o avanço do contágio, que já indicava se alastrar pelo Brasil ao fim do Carnaval, a Universidade Federal Fluminense (doravante UFF) bem como inúmeras instituições de ensino superior e básico, em março suspenderam todas as suas atividades presenciais. Tal medida impactou não apenas as aulas de graduação e pós-graduação do semestre que se iniciava, como também a execução das atividades de extensão da instituição, um dos três pilares das universidades brasileiras.

O objetivo do presente trabalho é apresentar um relato de experiência dos esforços empreendidos pelos instrutores e coordenadores dos cursos de língua alemã de um dos programas de extensão da UFF no ano de 2020, a fim de garantir o oferecimento remoto dos cursos já iniciados presencialmente na segunda semana de março de 2020, analisando para tal as percepções de alunos e professores em formação vinculados a esse projeto durante a fase do ensino remoto.

Primeiramente, apresentaremos brevemente o programa de extensão da UFF objeto de estudo do presente artigo, passando posteriormente à exposição acerca da metodologia utilizada nesse estudo e à análise dos dados coletados.

\section{0 programa de extensão PROLEM-UFF}

O Programa de Línguas Estrangeiras Modernas (doravante PROLEM) compõe o repertório de programas de extensão' oferecido pela Universidade à comunidade. Criado em 19972, promove o ensino de línguas estrangeiras à comunidade acadêmica e geral a baixos custos. O curso destaca-se pela promoção da diversidade linguística e multilinguismo (RIOULT et al, 2021, p. 114) por meio da ampla gama de línguas que oferta: alemão, espanhol, francês, inglês, italiano, esperanto, grego, guarani, japonês, latim, Libras, russo, yorubá, português instrumental e português para estrangeiros. Aos alunos de graduação e pós-graduação vinculados ao Instituto de Letras, o projeto emerge como espaço de reflexão da prática docente e atuação como professor-pesquisador (BORTONI-RICARDO,

1 Segundo dados da Pró-Reitoria de Extensão (ProEx), em 2019 a UFF contava com 1053 projetos cadastrados. (http://www.uff.br/?q=node/5237)

2 http://prolem.uff.br/apresentacao/ 
2008). Para tal, os professores-tutores são acompanhados e orientados por docentes do Instituto. Os professores em formação integrantes do projeto são selecionados semestralmente por meio de editais internos da universidade.

No âmbito do ensino de alemão, o curso é estruturado em nove semestres, que contemplam do nível A1 até o B1, seguindo o Quadro Comum de Referência Europeu (CONSELHO DA EUROPA, 2001). Além disso, há também a oferta de curso de revisão gramatical do nível A2. As turmas usualmente abrangem a faixa-etária de 18 a 60 anos, tendo uma média de 13 alunos por semestre.

\section{PROLEM pré-pandemia}

Como foi mencionado anteriormente, o PROLEM existe desde 1997 e representa um importante programa de extensão com dois objetivos bastante claros: oferecer à comunidade interna e externa à universidade acesso a cursos de línguas adicionais a preços acessíveis e oferecer aos graduandos e pós-graduandos em Letras um importante campo de estágio docente acompanhado por professores-coordenadores das respectivas línguas, professores do quadro efetivo do Instituto de Letras da UFF. Até o início de março de 2020, as aulas eram oferecidas unicamente em modalidade presencial, com aulas uma ou duas vezes por semana.

A mudança brusca para a modalidade online ou remota foi um grande desafio para praticamente todos os docentes, não só os de línguas adicionais. Por mais que se venha falando de "novas" tecnologias no ensino, a verdade é que pouco se implantou de fato em nosso país, de modo que a maioria dos docentes Brasil afora tiveram de improvisar ao serem obrigados a oferecer suas aulas em uma modalidade até então desconhecida. Nas palavras de Có, Amorim e Finardi (2020), que fizeram uma análise semelhante à proposta do artigo em tela, mas partindo apenas da percepção dos docentes de línguas:

\footnotetext{
Professores se viram forçados, da noite para o dia, a (re)pensar suas aulas no formato online sem uma (in)formação específica para isso. A situação excepcional que vivemos desde a instalação da pandemia impulsionou muitos professores de línguas a implementar o ensino emergencial no formato online (CÓ; AMORIM; FINARDI, 2020, p. 113-114).
}

Tal foi o caso dos cursos de alemão do programa de extensão da UFF ora analisado: consultados pela coordenação geral do programa de extensão de línguas estrangeiras, foi convocada uma reunião emergencial com os instrutores 
dos cursos, dos quais alguns já haviam tido pelo menos um encontro presencial. Foi-lhes feita a pergunta se teriam interesse e disponibilidade de encarar 0 desafio de ministrar as aulas de forma remota, síncrona, em ambiente virtual. A reação de todos foi bastante positiva e com isso passamos, nós, a equipe do PROLEM, a imaginar como essa transposição do presencial para o virtual seria feita, já que nem os instrutores nem os coordenadores possuíam realmente experiência nesse novo modelo ${ }^{3}$, que não é, como se sabe, educação a distância (EaD), mas sim ensino remoto emergencial (ERE):

O ensino emergencial é uma solução temporária de continuação de atividades pedagógicas tendo como principal ferramenta a internet e não se confunde com o ensino a distância ou EAD. O ensino a distância é uma modalidade planejada com apoio de tutores e recursos tecnológicos específicos com funcionamento e concepção didático-pedagógica própria abrangendo conteúdos, atividades e o processo avaliativo discente bem como questões de didática docente (CÓ; AMORIM; FINARDI, 2020, p. 114).

Para essa nova realidade de ERE, não existiam modelos realmente prontos. A formação dos futuros professores de alemão na UFF não contempla de forma satisfatória - e acreditamos que isso possa ser válido para a formação de professores de alemão no Brasil como um todo - suficientes matérias (principalmente obrigatórias) no currículo, seja no Instituto de Letras, seja na Faculdade de Educação, para dar conta de todos os desafios que a tecnologia (ou a falta dela) coloca para os docentes de um modo geral. As dificuldades técnicas nas universidades públicas também não são irrelevantes nesse contexto, já que internet de qualidade e computadores funcionando não são de fato uma realidade, pelo menos no caso da UFF. Além disso, não podemos negar que mesmo muitos de nós, professores universitários, não nos apropriamos ainda devidamente de uma quantidade suficiente de recursos tecnológicos e de suas possibilidades e vantagens para o ensino-aprendizagem de línguas adicionais, de modo que os professores-orientadores também foram lançados no desafio sem uma preparação prévia adequada 4 .

3 Na verdade, alguns instrutores já tinham alguma experiência com ensino mediado por tecnologia, como será visto na análise dos dados; os professores-coordenadores (um dos autores do artigo em tela e a profa. Dra. Mônica M. G. Savedra) já possuíam experiência em ensino a distância e/ou híbrido, bem como o uso de ferramentas para essas modalidades de ensino, mas não com o modelo remoto, online.

4 Como já foi mencionado acima, os professores-orientadores, um dois quais é co-autor do artigo em tela, possuem experiência com tecnologia no ensino e ambientes virtuais, estando em constante contato e em formações continuadas oferecidas pela própria universidade, pelo Goethe-Institut e pelo Serviço Alemão de Intercâmbio Acadêmico (DAAD), mas também não estavam preparados adequadamente 


\section{A inserção do PROLEM no ambiente online: ensino remoto emergen- cial, e-learning e blended learning}

A atual situação emergencial em que nos encontramos solidifica o aumento da necessidade do aprendizado sobre os meios de ensino e aprendizagem online e os métodos que os acompanham. Na posição de professor em formação (e atuante), torna-se imprescindível a busca pelo conhecimento sobre as principais metodologias baseadas em um ensino de qualidade acoplado à tecnologia. Seguindo essa linha de raciocínio, o seguinte segmento trabalhará os conceitos de Ensino Remoto Emergencial, e-Learning e Blended Learning (BL), apontando o que mais se alinha com o trabalho realizado no PROLEM durante a pandemia.

O Ensino Remoto Emergencial caracteriza-se como uma ação pedagógica, cuja função é transformar o ensino fornecido em formato presencial em um ensino intermediado por ferramentas tecnológicas digitais e/ou materiais fornecidos aos alunos (CHARCZUK, 2020). Sua principal função é fomentar e disponibilizar acesso ao ensino em situações críticas e anormais (HODGES, 2020). Ou seja, o ERM não é oferecido como tentativa de substituir ou reproduzir o ambiente educacional presencial, e sim, como uma alternativa temporária.

Faz-se novamente necessária a diferenciação entre ERM e EaD, termos que, frequentemente, são usados de forma equivocada. O EaD caracteriza-se pelo fato de ser planejado e direcionado para o formato online, podendo ser ou não completamente a distância. Conta também com o apoio extra de tutores e materiais das respectivas instituições e maior flexibilidade, uma vez que a maior parte das aulas é gravada anteriormente e, dentro do semestre estipulado, os alunos podem controlar suas horas. Além disso, as instituições que proporcionam o Ensino a Distância geralmente têm seus próprios ambientes virtuais de aprendizagem e as avaliações, quando presenciais, são aplicadas nos polos designados. Ademais, há parâmetros variáveis disponíveis para a configuração de um molde que funcione para cada situação específica:

para o desafio do ensino emergencial remoto, de modo que a preparação das próprias aulas da graduação e da pós-graduação também serviram de laboratório para o processo de co-construção do modelo remoto que foi implantado nos cursos livres de alemão do PROLEM-UFF. 


\section{Quadro 1 - Opções de design para o aprendizado online (variáveis moderadoras)}

Modalidade:

- Inteiramente online

- Blended (mais de 50\% online)

- Blended (25-50\% online)

- Captação face a face via internet

Ritmo

- Individualizado

- Ritmo da turma

- Ritmo da turma com um pouco de individualizado

Pedagogia

- Expositória

- Prática

- Exploratória

- Colaborativa

Papel do instrutor online

- Instrução ativa online

- Pequena presença online

- Nenhum

Papel das avaliações online

- Determinar se o aluno está pronto para novo conteúdo
- Dizer ao sistema como apoiar o aluno (instrução adaptável)

- Fornece ao aluno ou professor informações sobre o estado de aprendiz̧agem

- Nota

- Identifica alunos com risco de repetir

Comunicação síncrona online

- Somente assíncrona

- Somente síncrona

- Uma mistura dos dois

Papel do estudante online

- Ouvir ou ler

- Completar problemas ou responder questões

- Explorar simulações e recursos

- Colaborar com colegas

Fonte de feedback

- Automático

- Professor

- Colegas

Fonte: Conteúdo adaptado de Barbara Means, Marianne Bakia, and Robert Murphy, Learning Online: What Research Tells Us about Whether, When and How (New York: Routledge, 2014).

Em contrapartida, o ERM é uma medida excepcional e temporária, sendo, durante a pandemia no Brasil, regulado através do Parecer CNE/CP n 19/2020, com a finalidade de continuar o cronograma das atividades presenciais, porém no modelo online. No modelo mencionado, as aulas ocorrem usualmente ao vivo, contando com o apoio de plataformas de videoconferências e/ou aplicativos de redes sociais. As avaliações não são padronizadas e variam de acordo com as instituições, setores e professores. Por fim, as interações têm a tendência de manter 
o molde das que ocorriam presencialmente, quando há comunicação direta com o professor para resolução de dúvidas e afins, contudo adaptada às plataformas escolhidas.

A definição de e-Learning é um fator que gera divergências entre diversos autores. Galvin (p. 35) apresenta cinco diferentes perspectivas, sendo elas: a eletrônica, internet, tecnologias da internet, internet, CD ou DVD-ROM e mística. A primeira categoriza o e-Learning de forma mais ampla, como sendo um método de aprendizagem baseado em qualquer tipo de tecnologia, online ou offline. Já a segunda baseia-se nesses processos ocorrendo online, com o auxílio da internet. A seguinte definição trata-se das tecnologias da internet, utilizadas como recurso de compartilhamento de aprendizagem, tendo os seguintes fundamentos: ocorrer online, utilizar tecnologias standards da internet (como navegadores) e ter uma visão mais ampla da aprendizagem. Internet, CD ou DVD-ROM tem o processo apoiado por essas mesmas ferramentas. E, por último, a perspectiva mística descreve o e-Learning como o uso de tecnologias para expandir a aprendizagem.

Um ponto importante em comum entre todas as perspectivas apresentadas é o fato de o controle estar nas mãos dos alunos, em um meio onde eles possuem o controle de seu próprio aprendizado, ao invés de estarem inseridos em um meio controlado por seus professores e/ou instituições.

De acordo com Valente (2014, p. 83), existe uma multiplicidade entre os termos Ensino a Distância e e-Learning. Tal multiplicidade dá-se pelo fato de estarmos passando por um momento de transição do ambiente de aprendizado de Ensino a Distância tradicional, com base em materiais físicos e suportes tecnológicos limitados, para um ambiente composto por tecnologias mais atuais, como ambientes virtuais de aprendizagem e atividades de e-Learning. $O$ autor, porém, frisa que nem toda atividade de e-Learning é necessariamente realizada a distância, podendo ocorrer durante aulas presenciais ou encontros entre alunos, por exemplo.

Conforme elucida Whittaker (2013, p. 11), Blended Learning consiste na inclusão da tecnologia dos computadores, misturando atividades online e offline e outros materiais, no que já é implementado em sala de aula. Os alunos terão momentos em que trabalham e estudam o conteúdo apresentado utilizando ferramentas online, e outros em que essa etapa ocorre na sala de aula. Tayebinik e Puteh (2013) consideram o Blended Learning uma combinação de e-Learning e os já conhecidos ambientes de aprendizado. Ou seja, o fator chave da meto- 
dologia é diminuir os obstáculos de um ensino 100\% tradicional ou 100\% online, criando uma mistura eficaz de ambos.

O Blended Learning oferece flexibilidade e tempo individualizado com os alunos, permitindo que o ensino seja mais personalizado. Também promove a oportunidade de compreender um determinado tópico através de pré-determinados materiais online e complementando com a participação ativa em sala de aula e tarefas colaborativas, como o WebQuest. O Blended Learning funciona da seguinte maneira: através de materiais e introduções, os alunos são apresentados a uma problemática, que se tornará a tarefa em questão. O professor deve fornecer uma lista de fontes online a ser utilizada, uma descrição das etapas que os alunos deverão efetuar para que completem a atividade corretamente e orientações sobre como organizar e apresentar os resultados, seja através de vídeos, cartazes, etc. No fim, o professor deve fazer uma conclusão final e mostrar aos alunos o que eles aprenderam por conta própria (DODGE, 1995). Essa técnica ilustra a versatilidade do Blended Learning e como pode funcionar a mistura do online com o presencial.

Tendo em vista todas as definições apresentadas, a metodologia utilizada atualmente pelo PROLEM é o Ensino Remoto. Com o decreto da pandemia em março, logo após a primeira semana do início das atividades presenciais, a coordenação do programa optou por migrar para o ensino emergencial remoto. Houve, por parte da equipe de professores em formação, um processo de adaptação dos materiais e abordagens utilizadas, o que se reflete na análise dos dados.

\section{Metodologias e procedimentos}

A ideia para o presente artigo surgiu do interesse e das inquietações tanto dos professores-orientadores quanto dos professores em formação que atuavam como instrutores no âmbito do PROLEM em refletir sobre as suas práticas e analisar o que estava dando certo e o que eventualmente poderia ser melhorado, tentando compreender o processo através de duas perspectivas: a percepção dos alunos dos cursos de alemão do PROLEM e dos instrutores atuantes no programa naquele momento. Duas das autoras deste estudo estavam atuando elas mesmas como instrutoras dos cursos de alemão durante o estudo. Para não enviesar os resultados, as duas não participaram da pesquisa como informantes, mas sua atuação como instrutoras as coloca em posição de entender melhor as falas dos colegas instrutores. Trata-se, portanto, de uma reflexão sobre sua prática, mas que não as inclui no corpus analisado. 
Para obter respostas que pudessem ajudar a entender melhor, foram confeccionados dois questionários online com a ferramenta Survey Monkey ${ }^{\circledR}$ (anexos 1 e 2), que continham perguntas relativas à percepção dos instrutores e dos alunos acerca das aulas no modelo remoto, que foi algo novo para a grande maioria. Os formulários foram disponibilizados em outubro de 2020 para os 9 instrutores e para os mais de 300 participantes dos cursos de alemão no segundo semestre de 2020. Dos instrutores, 7 responderam às perguntas e dos alunos, tivemos a resposta de 102 pessoas. O questionário para os alunos consistia de 9 perguntas, sendo 3 fechadas e 6 semiabertas (com possibilidade de comentários) e que versavam sobre suas experiências com tecnologias no ensino remoto até aquele momento da pandemia e suas primeiras impressões acerca dessa modalidade de ensino no curso de alemão do PROLEM. O questionário enviado aos instrutores, por sua vez, contava com 10 perguntas, sendo 4 fechadas e 6 semiabertas. Neste, procuramos mensurar suas experiências antecessoras no âmbito do ensino online, a presença de disciplinas voltadas ao uso de tecnologias durante a formação docente e suas avaliações acerca do semestre remoto no PROLEM.

Pode-se afirmar que se trata de uma pesquisa de abordagem mista (BORTONI-RICARDO, 2008), pois ainda que tenhamos dados quantitativos com um número de participantes relativamente alto entre os alunos e entre os instrutores - já que nosso universo de pesquisa pretendia abranger unicamente a experiência feita no âmbito dos cursos de alemão do PROLEM - nosso objetivo era aferir qualitativamente as percepções de um grupo específico de instrutores e de alunos de cursos de alemão durante a pandemia, o que pôde ser medido através dos comentários feitos por ambos os grupos. Apesar de se tratar de um grupo e contexto específicos, os dados aqui obtidos podem servir de elementos para comparação com outros contextos semelhantes. Um estudo semelhante publicado recentemente, mas que se refere apenas à percepção dos aprendizes de alemão de um curso livre em uma universidade, foi publicado por Garcia D'Avila Menezes (2021).

\section{Transição para o online}

Com o início da pandemia, a equipe de professores em formação de língua alemã no PROLEM precisou passar por rápidas mudanças para se adaptar. É interessante notar que esse foi o primeiro curso de extensão das três universidades públicas com formação de professores de alemão no estado do Rio de Janeiro a adaptar as aulas para esse novo modelo, os demais passariam a ofertar 
cursos na modalidade online apenas no segundo semestre ${ }^{5}$.

O número de alunos inscritos nos cursos de alemão no PROLEM em março de 2020, antes do início oficial da pandemia, era de 179 alunos, em cursos de níveis A1 a B1. Após algumas semanas, com a informação de que as aulas iriam prosseguir no modo remoto, houve a possibilidade de os alunos desistirem da inscrição caso não se sentissem confortáveis com o novo modelo. No início de maio havia restado 136, uma taxa de desistência de mais de $20 \%$. Há de se considerar que nem todos necessariamente desistiram por causa do novo modelo de ensino remoto, já que as flutuações de inscrições e desistências são normais em todo início de semestre nos cursos do projeto. Uma pesquisa de satisfação pela secretaria do PROLEM junto aos alunos, da qual participaram 80 alunos, mostrou uma satisfação bastante grande com a qualidade das aulas, manifestando porém dificuldades com o uso do Google Meet, o que motivou a mudança institucional para o Zoom, que demonstrou ser mais adequado ao modelo emergencial remoto, como será visto mais adiante. O sucesso dos cursos do PROLEM parece ter repercutido bastante, pois no segundo semestre de 2020 as inscrições nos cursos de alemão tiveram um salto de geralmente pouco menos de 200 por semestre, para 331, com participantes de várias regiões do Brasil, como foi o caso de várias instituições de ensino em todo o país.

\subsection{Adaptação: escolha das plataformas e ajustes}

Inicialmente foi usado o Google Meet por questões de vínculos da UFF com o Google for Education, serviço oferecido pela Google. Além disso, buscamos utilizar mais ferramentas oferecidas por esta, como Google Slides e Google Drive.

Ao longo do semestre, alguns instrutores perceberam que, por falta de recursos da plataforma utilizada para as aulas síncronas, o Zoom seria uma opção melhor. Com a possibilidade de dividir os alunos em grupos menores, utilizar um quadro virtual para poder escrever, dispor de melhor qualidade de compartilha-

5 Nesse contexto, é relevante mencionar que foi oferecida uma formação para os instrutores de língua alemã dos programas de extensão da UERJ, UFRJ e UFF durante três semanas em julho de 2020. Tratouse de uma iniciativa dos docentes da UFF para oferecer aos três programas (LICOM, CLAC e PROLEM, respectivamente) uma qualificação em ferramentas tecnológicas para o ensino-aprendizagem de língua alemã e principalmente sua aplicação/aplicabilidade no contexto do ensino emergencial remoto. Os alunos da UFF puderam contribuir com sua experiência prática prévia durante o semestre de 2020-1. Participaram do curso 32 graduandos e mestrandos das três universidades, bem como seis professores, dois de cada uma, dentre os quais dois colegas do Serviço Alemão de Intercâmbio Acadêmico (DAAD), atuantes na UERJ e na UFRJ. 
mento de áudio, entre outros, a plataforma ofertou um maior dinamismo e diminuiu a frequência de aulas extremamente expositivas. O PROLEM, entendendo a necessidade dessa ferramenta para o bom andamento das aulas, providenciou contas para o Zoom que foram utilizadas de forma padronizada no semestre de 2020-2.

Outro importante fator para o funcionamento do semestre online foi a elaboração das avaliações. Os instrutores, divididos pelos níveis sob suas responsabilidades, organizaram de forma colaborativa provas escritas e orais. Assim como era feito no formato presencial, os professores em formação pesquisaram diversas questões relacionadas ao conteúdo aprendido e um deles, escolhido previamente, tinha a função de montar a avaliação com base no material fornecido. Em seguida, o responsável enviava as provas para os coordenadores, que então revisavam o trabalho executado. Tal sistema permaneceu na transição para o ensino remoto. A aplicação ficou a critério dos instrutores, alguns optando por enviar o arquivo em formato PDF via e-mail ou Google Drive para os alunos, enquanto outros utilizaram a ferramenta Google Forms, que também auxiliou na correção.

\subsection{Preparação}

Na enquete realizada entre os professores em formação da área de língua alemã do PROLEM, constatou-se que $75 \%$ dos 7 participantes não haviam tido experiências anteriores com o ensino online. Pelo fato de o currículo da UFF não ter disciplinas que contemplam satisfatoriamente o campo, a fase de adaptação ao novo formato partiu dos próprios professores, com o apoio dos coordenadores. No início, cada um pesquisou por conta própria metodologias e materiais que poderiam funcionar e todas as novas descobertas eram compartilhadas. Além disso, como alguns dos instrutores haviam cursado a matéria optativa "Tecnologias Digitais no Ensino de Línguas Estrangeiras", ministrada pela professora Dr. Cintia Regina Lacerda Rabello na UFF, diversas plataformas e ferramentas que tinham o potencial de ser utilizadas foram melhor aproveitadas. Já no segundo semestre de ensino emergencial, participamos de um curso online organizado por docentes dos setores de alemão da UFF, UERJ e UFRJ e leitores do Serviço Alemão de Intercâmbio Acadêmico (DAAD), quando foram trabalhadas, de forma prática, questões como planejamento de aulas, treino das habilidades e ferramentas úteis. Salienta-se ainda que, durante a pandemia, os professores tiveram e continuam tendo a oportunidade de, por conta própria, participar de diversos cursos de formação voltados para o ensino de língua alemã na modalidade onli- 
ne.

\section{Análise dos dados dos questionários entre os alunos}

Como foi dito anteriormente, houve 102 respostas à enquete online disponibilizada aos mais de 300 alunos dos cursos de alemão do PROLEM ${ }^{6}$. À pergunta sobre experiência(s) prévia(s) com ensino online de idiomas, 78\% responderam que não, 18\% que sim, 5\% apenas com Ensino a Distância (sem interação por Zoom, Skype, Meet etc.) e outros 5\% disseram que apenas com modelo híbrido (aulas presenciais e atividades a distância, em plataformas).

Em resposta à segunda pergunta, apenas $5 \%$ dos respondentes disseram ter iniciado o curso no PROLEM ainda na modalidade presencial; 95\% disseram ter iniciado seus cursos já na modalidade online. Pode-se atribuir tal resposta à grande procura pelos cursos oferecidos pelo PROLEM no segundo semestre de 2020, tendo sido necessária a duplicação de todas as 5 turmas de iniciantes oferecidas. Essa suposição é corroborada pelas respostas à terceira pergunta, na qual $67,5 \%$ afirmaram nunca ter estudado alemão antes, e 32,5\% já havia estudado alemão em modalidade presencial.

Quanto à experiência que estavam tendo com o ensino online no PROLEM, 75\% consideraram-na ótima, 17,5\% boa, 5\% regular e apenas 2,5\% péssima. Apesar de se tratar de uma pergunta que permitia a opção de comentários, não houve nenhum. Questionados acerca dos pontos positivos do modelo em que estavam estudando alemão, $5 \%$ disse que nada chamava a atenção positivamente, $10 \%$ mencionou o uso de aplicativos e de elementos lúdicos, enquanto que $77,5 \%$ consideraram a interação entre instrutor e alunos como um ponto positivo. Apenas 7,5\% preferiram comentar e destacaram a praticidade/flexibilidade do modelo remoto; $72,5 \%$ dos respondentes afirmaram que nada Ihes chamou a atenção negativamente no modelo online, $10 \%$ consideraram negativa a interação entre instrutor e aluno; $17,5 \%$ comentaram que as dificuldades eram fundamentalmente de ordem técnica, principalmente no que tange à conexão, apenas dois respondentes destacaram que isso teria uma influência negativa na interação em aula:

Respondente 16: A professora não pode ter uma noção muito clara sobre o aprendizado individual de cada aluno, outros problemas foram externos, como a luz ou

6 Não se pode precisar o número exato de inscritos no momento exato da pesquisa, nem quantos efetivamente receberam o link para ela, mas cremos que foram pouco mais de 300. 
internet cair/variar.

Respondente 29: Acho que a interação ficou um pouco mais lenta pois o ritmo online não eh (sic) o mesmo. Mas ainda sim muito bom.

Ao compararem a experiência que estavam tendo com experiências anteriores de ensino de alemão, caso as tivessem tido, 67\% disseram ser a experiência atual positiva; 6\% afirmaram estar sendo regular; $27 \%$ afirmaram não ter tido experiência anterior com o ensino de alemão; 92,5\% dos respondentes afirmaram que continuariam a aprender alemão na modalidade online; $5 \%$ disseram que não pretendiam continuar na modalidade online, enquanto 2,5\% disseram não saber ainda.

A última pergunta, que era mais aberta, teve 60\% de respostas "nada", i.e. sem comentários. Os 40\% que responderam, fizeram vários comentários, e a grande maioria se referia à necessidade da manutenção da oferta online. Os outros comentários se referiam a elogios específicos a instrutores.

\footnotetext{
Respondente 40: Não conseguiria estudar alemão na UFF se fosse presencial, pois moro longe. A opção aos sábados é ótima pois atende quem trabalha, mas poderia começar um pouco mais tarde, talvez 9h ou 9:30h.
}

Respondente 5: O modelo online é muito bom, pq (sic) evita gasto de tempo de deslocamento, se fosse presencial seria impossível fazer o Prolem.

À guisa de conclusão parcial, pode-se dizer que a grande maioria dos alunos teve uma percepção positiva da experiência online e gostariam de continuar. Mais adiante faremos uma discussão mais aprofundada, após analisarmos os dados dos questionários dos instrutores.

\section{Desenrolar do semestre: pontos positivos e negativos}

No grupo de graduandos e pós-graduandos selecionados para ministrar aulas durante 2020,50\% começaram a dar aula online antes da pandemia, isto é, já atuavam no projeto pelo menos desde 2019. No entanto, 37,5\% iniciaram suas atividades poucos dias antes da suspensão das atividades presenciais da universidade e 12,50\% ingressaram no PROLEM diretamente na modalidade remota emergencial, assumindo turmas apenas no segundo semestre.

Os resultados dos questionários realizados com esses professores em formação apontam que $75 \%$ não possuíam experiência com aulas online. O contato dos demais com essa modalidade de ensino se dera por meio de três situações: em alguns casos como alunos em cursos a distância, já em outros atuando como 
professores de línguas adicionais, seja em aulas particulares ou como instrutores presenciais da plataforma DUO, vinculada ao projeto Alemão sem Fronteiras (ISF), por meio da cooperação fomentada pelo Ministério da Educação entre as universidades federais, dentre elas a UFF e o DAAD. É interessante notar que apesar do currículo de licenciatura da UFF, como supracitado, não ofertar disciplinas obrigatórias relacionadas ao uso de mídias e tecnologias digitais na prática docente, 33,5\% dos respondentes procuraram seminários optativos, cursos livres ou atividades de extensão acerca dessa temática, demonstrando que já antes da pandemia emergia uma preocupação dos graduandos em suprir essa lacuna em sua formação.

Esse cenário, sem dúvidas, alterou-se drasticamente em virtude da conjuntura engendrada pela COVID-19. A partir das urgentes demandas no processo de adaptação das aulas para o novo formato, $75 \%$ dos respondentes realizaram cursos de formação voltados ao ensino de alemão na modalidade online. Os inúmeros cursos e workshops oferecidos logo no primeiro semestre, possibilitaram que os instrutores pudessem ampliar seu repertório de aplicativos, jogos e métodos. Nesse ínterim, destacaram dois participantes do questionário:

Respondente 1: Fiz o curso proposto pela UFF/UFRJ/UERJ/DAAD foi interativo e informativo, produção acadêmica, dinâmicas.

Respondente 2: Foi bem interessante porque foram apresentados varias (sic) plantaformas (sic) que eu nao (sic) conhecia.

Essa variada experiência construída ao longo do ensino remoto emergencial, ainda que em níveis distintos, foram vistas de modo positivo; 37,50\% dos professores em formação consideraram ótimas as aulas online; $50 \%$ bom e apenas 12,50\% regular. Sabendo que a UFF atende alunos oriundos não só de Niterói, mas também de diferentes cidades de seu entorno, a redução do tempo de deslocamento e do gasto com as passagens não nos surpreende de constar entre os aspectos positivos. Assim relata um sujeito da pesquisa:

Respondente 3: O mais positivo, na minha opinião foi não ter que me deslocar da minha casa até o curso e gasto de passagem. (...)

A possibilidade de utilizar novas plataformas, materiais e recursos online, antes restritos devido à limitação estrutural da universidade, como por exemplo, a falta de conexão acessível e estável para o uso do professor e dos alunos, agradaram nossos respondentes. Nesse âmbito, 75\% dos instrutores destacaram posi- 
tivamente o uso de aplicativos e atividades lúdicas, 12,50\% as novas interações entre alunos e professor e 12,50\% elencam outras motivações, como vemos a seguir:

Respondente 3: (...) Além disso, podemos fazer atividades que não seriam possíveis em sala de aula por causa dos dispositivos eletrônicos.

Respondente 4: Produção de materiais didáticos e exercícios

Por fim, também emergiu nos relatos como um aspecto positivo a ampliação e a diversificação do perfil dos alunos em decorrência do maior alcance do curso.

Se por um lado o ambiente online abriu novas possibilidades de interação, como já citado, por outro também dificultou, segundo 37,50\% dos entrevistados, a interação entre alunos e professores. Os motivos para tal são variados. Acerca do componente material, os instrutores relataram dificuldades para manejar os novos recursos, bem como na oferta de recursos técnicos adequados. Alguns instrutores, por exemplo, não possuíam eletrônicos com capacidade operacional para executar os programas com facilidade ${ }^{7}$ ou possuíam pacotes de internet restritos:

Respondente 5: Minha primeira aula, onde diversos imprevistos técnicos ocorreram e prejudicaram muito o encontro.

Ainda no âmbito das interações interpessoais, detectou-se também a falta de engajamento de alguns alunos inscritos, manifestada sob diferentes formas. Os professores se depararam ao longo do semestre com alunos que se recusaram a abrir câmeras durante as atividades em aula, com os que só queriam assistir a aula passivamente e sem interagir com os colegas e com aqueles que assistiam às aulas enquanto faziam outras atividades concomitantemente. De acordo com um dos instrutores:

Respondente 6: Eu sempre chamo um aluno e ele nunca respondia, depois ele aparecia e perguntava onde estava, o q (sic) era pra fazer.

Também chamou a atenção negativamente, de acordo com 25\% dos entrevistados, a extensa carga horária às quais os instrutores foram submetidos, queixa compartilhada por docentes dos mais diferentes segmentos tanto da esfera pública quanto privada (AMORIM, 2020). Já 25\% não identificaram qualquer

7 Aos professores que não possuíam acesso a computadores em casa foram disponibilizados laptops durante o período remoto pela secretaria do curso. 
aspecto negativo e 12,50\% afirmaram ter outros aspectos negativos tais como a manutenção da mesma carga horária do curso presencial na modalidade remota:

Respondente 4: Alguns alunos apresentaram indisposição para aulas com tempo superior à $3 h$ de duração.

Respondente 1: Aumentou o trabalho, cansaço, apesar da boa disposição.

Ao comparar com a experiência anterior, em caráter presencial, e a experiência online atual, $75 \%$ avaliaram positivamente a nova modalidade, 12,5\% acharam regular e 12,5\% declararam outro, contudo, não descreveram. A despeito de todas as contradições e dificuldades enfrentadas, fora consenso entre os respondentes o desejo por continuar a ministrar aulas de alemão no modelo online após essa experiência.

\section{Considerações Finais}

O artigo teve como seu principal objetivo relatar a experiência prática dos instrutores e coordenadores do setor de alemão do PROLEM durante o período de pandemia. Nessa perspectiva, tanto os instrutores quanto os alunos participantes da pesquisa forneceram respostas positivas sobre o funcionamento do curso no modelo emergencial.

Notou-se uma evidente carência de disciplinas na grade curricular da UFF que contemplassem metodologias e técnicas de ensino voltados para o ambiente online. Por mais que vários cursos tenham sido organizados e disponibilizados para a comunidade acadêmica e em geral, a área de ensino e aprendizado online precisa se tornar mais presente nas universidades, uma vez que é uma competência de extrema relevância para a formação de professores. Apesar disso, a equipe procurou desenvolver suas competências digitais e conhecer novas metodologias para fornecer o melhor ensino possível para os estudantes, criando uma rede de cooperação e divulgação de artigos, materiais e ferramentas tecnológicas.

Ainda no contexto apresentado, concluímos que, apesar das dificuldades decorrentes do ensino emergencial, o curso teve uma boa repercussão entre o público. Como resultado, observamos que a ampliação da oferta de cursos de extensão para a modalidade remota aparenta vir de encontro com a demanda de um fragmento da comunidade externa e que, nesta medida, contribui para a 
democratização e expansão do acesso ao ensino.

\section{Referências}

AMORIM, A. G. P. Ambiente Virtual de Aprendizagem - Moodle: Possibilidades de autoria, gestão e colaboração na educação básica e na pós-graduação. In: LIBERALI, F. C. et al. (Org.). Educação em tempos de pandemia: brincando com um mundo possível. Campinas, SP: Pontes Editores, 2020, p. 65-71.

BORTONI-RICARDO, S. M. O Professor-Pesquisador: uma introdução à pesquisa qualitativa. São Paulo: Parábola Editorial, 2008.

BRASIL, Conselho Nacional de Educação. Parecer CNE/CP n 19, de 8 de dezembro de 2020, das Diretrizes Nacionais para a implementação dos dispositivos da Lei $n^{\circ} 14.040$, de 18 de agosto de 2020, que estabelece normas educacionais excepcionais a serem adotadas durante o estado de calamidade pública reconhecido pelo Decreto Legislativo $n^{\circ}$ 6, de 20 de março de 2020. Brasília, Diário Oficial da União, seção 1, p. 106, 10 de dezembro.

CHARCZUK, S.B. Sustentar a Transferência no Ensino Remoto: docência em tempos de pandemia. Educ. Real., Porto Alegre, v. 45, n. 4, 2020. Disponível em: http://www.scielo.br/scielo. php?script=sci_arttext\&pid=S2175-62362020000400206\&lng=en\&nrm=iso. Acesso em: 15 fev. 2021.

CÓ, E. P.; AMORIM, G. B.; FINARDI, K. R. Ensino de línguas em tempos de pandemia: experiências com tecnologias em ambientes virtuais. Redoc, Rio de Janeiro, v. 4, n. 3, p. 112, set./dez. 2020. Disponível em: https://doi.org/10.12957/redoc.2020.53173. Acesso em: 26 fev. 2021.

CONSELHO DA EUROPA. Quadro comum europeu de referência para as línguas:

aprendizagem, ensino, avaliação. Edição portuguesa. Porto: Edições Asa, 2001. Disponível em: http://area.dge.mec.pt/gramatica/Quadro_Europeu_total.pdf. Acesso em: 15 fev. 2021.

DODGE, B. WebQuests: A Technique for Internet - Based Learning. San Diego State University, 1995. Disponível em: https://www.researchgate.net/publication/234648506_WebQuests_A_Technique_for_Internet-Based_Learning. Acesso em: 15 fev. 2021.

GALVIN, C. E-Learning e o Ensino-Aprendizagem. In: LIMA, J. R.; CAPITÃO, Z. e-Learning e e-Conteúdos. Portugal: Centro Atlântico, 2003, p. 35.

GARCIA D'AVILA MENEZES, R. Adaptação de um curso de alemão em contexto acadêmico para o ensino remoto emergencial através de metodologias ativas. Signo, Santa Cruz do Sul, v. 46, n. 85, p. 170-179, jan. 2021. ISSN 1982-2014. Disponível em: https://online.unisc.br/seer/index.php/signo/article/view/15675. Acesso em: 15 fev. 2021.

HODGES, C. et al. The difference between emergency remote teaching and online learning. EDUCAUSE, 2020. Disponível em: https://er.educause.edu/articles/2020/3/the-difference-between-emergency-remote-teaching-and-online-learning. Acesso em: 15 fev. 2021.

LIBERALI, F. C. Construir o inédito viável em meio à crise do coronavírus - lições que aprendemos, vivemos e propomos. In: LIBERALI, F. C. et al. (Org.) Educação em tempos de pandemia: brincando com um mundo possível. Campinas, SP: Pontes Editores, 2020, p. 13-21.

MAYES, T.; DE FREITAS, S. Learning and e-learning: the role of theory. In: BEETHAM, H.; SHARPE, R. Rethinking Pedagogy for a Digital Age: designing and delivering e-learning. New York: Routledge, 2007, p. 13-25.

MEANS, B.; BAKIA, M.; MURPHY, R. Learning Online: What Research Tells Us about Whether, When and How. New York: Routledge, 2014. 
RIOULT, N.; MARRON, A.; PEREIRA, T. Aulas virtuais: uma discussão sobre a interação no aprendizado de língua estrangeira em tempos de pandemia. Signo, Santa Cruz do Sul, v. 46, n. 85, p. 108-121, jan. 2021. Disponível em https://online.unisc.br/seer/index.php/signo/article/ view/15617. Acesso em: 02. fev. 2021.

TAYEBINIK, M.; PUTEH, M. Blended Learning or E-learning? International Magazine on Advances in Computer Science and Telecommunications - IMACST. Disponivel em https://arxiv.org/ abs/1306.4085. Acesso em: 15. fev. 2021.

VALENTE, J. A. Blended Learning e as mudanças no ensino superior: a proposta de sala de aula invertida. Educar em Revista, Curitiba, n. 4, p. 82-85, 2014.

WHITTAKER C. Introduction. In: TOMLINSON, B.; WHITTAKER C. Blended Learning in English Language Teaching: Course Design and Implementation. Londres: British Council, 2013.

\section{Sobre os autores}

Marina Lopes Ribeiro - Graduanda em Letras: Português-Alemão e professora-tutora no Programa de Línguas Estrangeiras Modernas (PROLEM) da Universidade Federal Fluminense (UFF); Niterói-RJ. E-mail: maribeiro@id.uff.br. Lattes: http://lattes.cnpq. br/7768538448640688. OrclD: https://orcid.org/0000-0002-4960-6711

Stephanie Godiva - Graduanda em Letras: Português-Alemão e ex-professora-tutora no Programa de Línguas Estrangeiras Modernas (PROLEM) da Universidade Federal Fluminense (UFF); Niterói-RJ. E-mail: stephaniegodiva@id.uff.br. Lattes: http://lattes. cnpq.br/4108257892960120. OrclD: https://orcid.org/0000-0002-4268-0476

Ebal Sant'Anna Bolacio Filho - Doutor em Letras. Professor adjunto de língua alemã da Universidade Federal Fluminense (UFF) e do Programa de Pós-Graduação em Letras (Estudos de Língua) da UFF (UERJ); Niterói-RJ. E-mail: ebolacio@gmail.com. Lattes: http://lattes.cnpq.br/8998118373500736. OrclD: https://orcid.org/0000-0002-6050-5591. 


\section{Anexo 1}

Questionário online disponibilizado aos alunos dos cursos de alemão do PROLEM no semestre de 2020-1

1. Você já tinha tido experiência com aulas online de idiomas?

2. Você iniciou o curso no Prolem na modalidade presencial?

3. Você já havia estudado alemão antes, em modalidade presencial?

4. Como foi sua experiência até agora com o ensino de alemão online?

5. O que mais chamou sua atenção positivamente nessa experiência de ensino online de alemão?

6. O que mais chamou sua atenção negativamente nessa experiência de ensino online de alemão?

7. Comparando sua experiência anterior (caso tenha tido) no ensino de alemão como avalia a experiência online atual?

8. Você continuaria a estudar alemão no modelo online após essa experiência?

9. O que mais gostaria de comentar? 


\section{Anexo 2}

Questionário online disponibilizado aos instrutores dos cursos de alemão do PROLEM no semestre de 2020-1

1. Você já tinha tido experiência com ministrando aulas online de idiomas?

2. Durante sua formação acadêmica você cursou alguma disciplina ou atividade de extensão relacionada ao ensino online?

3. Você realizou algum curso de formação voltado ao ensino de alemão na modalidade online durante a pandemia?

4. Você iniciou o curso no Prolem na modalidade presencial?

5. Como foi sua experiência até agora com o ensino de alemão online?

6. O que mais chamou sua atenção positivamente nessa experiência de ensino online de alemão?

7. $\bigcirc$ que chamou sua atenção negativamente nessa experiência de ensino online de alemão?

8. Comparando a experiência anterior (caso tenha tido) como professor de alemão, como avalia a experiência online atual?

9. Você continuaria a ministrar aulas de alemão no modelo online após essa experiência?

10. O que mais gostaria de comentar? 